\title{
Design and parametric evaluation of UWB antenna for array arrangement
}

\author{
Faraz Ahmed Shaikh ${ }^{1}$, Sheroz Khan ${ }^{2}$, A. H. M. Zahirul Alam ${ }^{3}$, Dominique Baillargeat ${ }^{4}$, Mohamed \\ Hadi Habaebi ${ }^{5}$, Mashkuri Bin Yaacob ${ }^{6}$, Jawad Shah $^{7}$, Zeeshan Shahid ${ }^{8}$ \\ ${ }^{12,3,5,6}$ Department of Electrical and Computer Engineering, International Islamic University, Malaysia \\ ${ }^{4}$ Department of Research XLIM, University of Limoges, France \\ ${ }^{7}$ Department of Electrical Engineering, Universiti Kuala Lumpur (UniKL), Malaysia \\ ${ }^{8}$ Department of Electrical Engineering Institute of Business Management, Pakistan
}

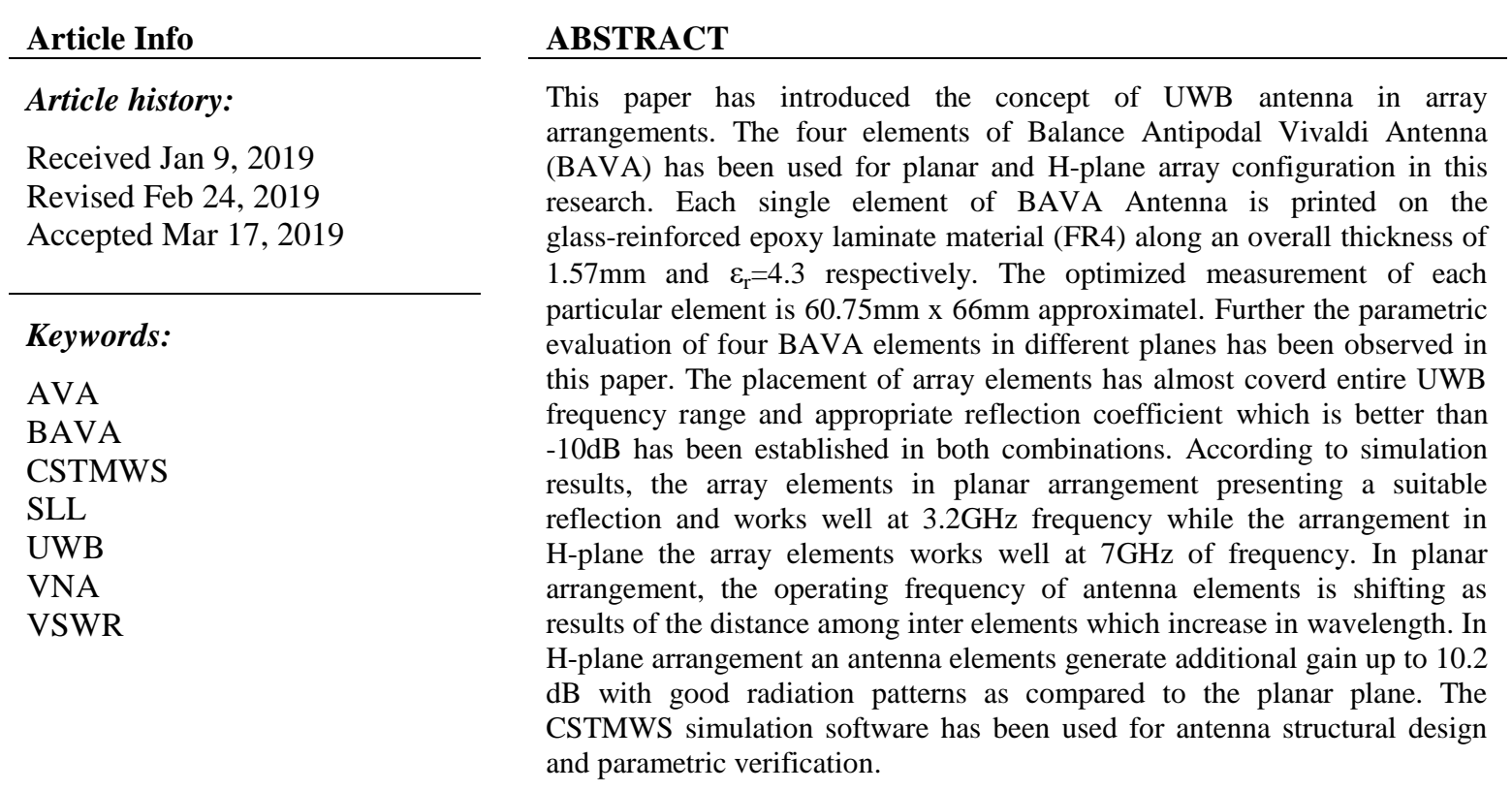

Copyright $\odot 2019$ Institute of Advanced Engineering and Science. All rights reserved.

\section{Corresponding Author:}

Faraz Ahmed Shaikh,

Department of Electrical and Computer Engineering,

International Islamic University Malaysia (IIUM),

P.O. Box 10, 50728 Kuala Lumpur, Malaysia.

Email: farshaikh@uit.edu

\section{INTRODUCTION}

In an array system the use of ultra-wide band has become an ultimate choice of several scholars [1-3] Currently, these types of systems are playing a vibrant role in different radar and imaging applications $[4,5]$. In modern research about medical sciences the use of compact array system which gives high resolution and precise results are generally required for the detection of different stages of cancer [6-8]. The special high gain antennas with compact in structure are commonly used in designing scheme of these kinds of systems and it gives a good impact especially in medical sciences. It shows a valuable contribution in further applications such as satellite communication system and technology [9].

Initially the concept of Antipodal Vivaldi antenna has been discussed by Gazit [10]. A high amount of gain and better directivity with low side lobe level has achieved under UWB frequency range from the use of AVA in many application [11-14]. For further betterment and improvement in term of performance 
parameters an equal slits line has introduced at the both edge of an antenna called Balance antipodal Vivaldi antenna $[15,16]$. Now BAVA has been considered as a suitable alternative in many applications.

In this research an elliptical shaped structure with equal slits line for the formation of BAVA array configuration is introduced. The comparison analysis of two types of planes which are planar plane and $\mathrm{H}$-plane in a capacity of reflection coefficient, voltage standing wave ratio, gain or directivity and side lobe level has been discussed in this paper [17].

\section{SINGLE ELEMENT DESIGN AND CONFIGURATION}

The design concept of antipodal Vivaldi antenna on simulation software has two exponentially tapered slot confined by inner and outer edges using a substrate material of FR4 which has a low cost in nature. The material has a dielectric constant value $\varepsilon_{\mathrm{r}}=4.3$, requiring a total thickness of $\mathrm{h}=1.57 \mathrm{~mm}$ and dielectric loss value which is $\delta=0.02$ respectively. The representation of basic geometrical structure of AVA is shown in Figure 1.

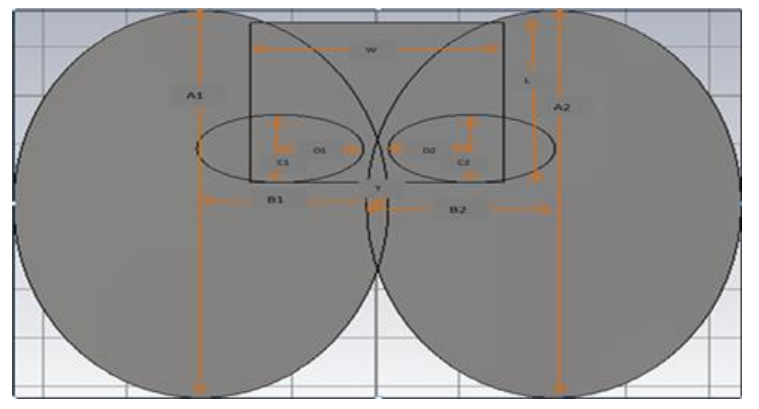

Figure 1. Geometry of the antipodal Vivaldi antenna [17]

This design of an antenna is depending upon two main parts such as a feed lines and radiation flares of an antenna [18-20]. An elliptical curve structure is used for the formation of BAVA and this type of structure provides respectable broadband characteristics because of smooth transition [21] and it is developing an excellent connection among the two parts of an antenna. Hypothetically, the effective parameters of an antenna can be calculated by the following [22].

$$
\mathrm{fmin}=\frac{\mathrm{c}}{2 \mathrm{~W} \sqrt{\varepsilon_{\mathrm{eff}}}}
$$

The upper limit of an antenna which is considers being infinity. The representation of lower limit depends upon the following factors which are width and effective dielectric constant $\left(\varepsilon_{\text {eff }}\right)$ values of an antenna respectively.

$$
\varepsilon_{e f f}=\frac{\varepsilon_{r}+1}{2}+\frac{\varepsilon_{r}-1}{2}\left(1+\frac{12 h}{w}\right)^{-1 / 2}
$$

The AVA geometrical structure consists of four elliptical curves. The two big curves are vertically mounted with two other curves which are placed horizontal. For the transformation of BAVA, some modification such as slits lines with equal in dimension placed at the edges side of an AVA antenna. It provides good radiation and smooth transition among the radiation flares shown is Figure 2.

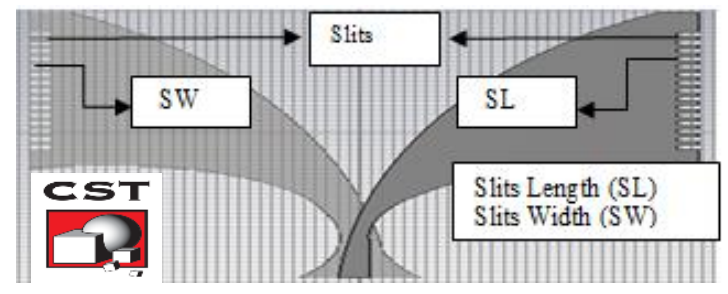

Figure 2. Balanced antipodal Vivaldi antenna (BAVA) [17] 
The BAVA is working an UWB frequency range and feed line has a fixed width which achieved a characteristic impedance $Z_{0}=50 \Omega$. The CST computer simulation software has been used for derived the results [23, 24]. Theoretically, following equations such as (3) and (4) will be considered for impedance calculation [25]. The optimized measurements of BAVA are declared in Table 1.

$$
\begin{aligned}
& z_{o}=\frac{60}{\sqrt{\varepsilon_{\text {eff }}}} \ln \left(\frac{8 h}{w}+\frac{w}{4 h}\right) \text { for }\left(\frac{w}{h}\right)<1 \\
& z_{O}=\frac{120 \pi}{\sqrt{\varepsilon_{\text {eff }}}\left[\frac{w}{h}+1.393+\frac{2}{3} \ln \left(\frac{w}{h}+1.444\right)\right]} \text { for }\left(\frac{w}{h}\right) \geq 1
\end{aligned}
$$

Table 1. Optimized dimensions for the UWB Antenna [17]

\begin{tabular}{cc}
\hline Parameter & Dimension \\
\hline W & $60.75 \mathrm{~mm}$ \\
$\mathrm{~L}$ & $66 \mathrm{~mm}$ \\
$\mathrm{~A} 1$ & $80 \mathrm{~mm}$ \\
$\mathrm{~B} 1$ & $22.5 \mathrm{~mm}$ \\
$\mathrm{~A} 2$ & $80 \mathrm{~mm}$ \\
$\mathrm{~B} 2$ & $22.5 \mathrm{~mm}$ \\
$\mathrm{C} 1$ & $14 \mathrm{~mm}$ \\
$\mathrm{D} 1$ & $10 \mathrm{~mm}$ \\
$\mathrm{C} 2$ & $14 \mathrm{~mm}$ \\
$\mathrm{D} 2$ & $10 \mathrm{~mm}$ \\
T(feed width) & $2.85 \mathrm{~mm}$ \\
SL & $1 \mathrm{~mm}$ \\
SW & $2 \mathrm{~mm}$ \\
$\mathrm{~h}$ & $1.5 \mathrm{~mm}$ \\
$\mathrm{t}$ & $0.035 \mathrm{~mm}$ \\
\hline
\end{tabular}

\subsection{Reflection coefficient}

The simulation and experimental results of single element of BAVA antenna represents the reflection coefficient $\left(S_{11}\right)$ under UWB frequency range as shown in Figure 3 and Figure 4. It is perceived that given antenna almost cover UWB defined frequency range and maximum reflection coefficient $\left(S_{11}\right)$ simulation based which is around $-55.45 \mathrm{~dB}$ and $-41.5 \mathrm{~dB}$ experiment based at certain frequency which is suitable for imaging and others application.

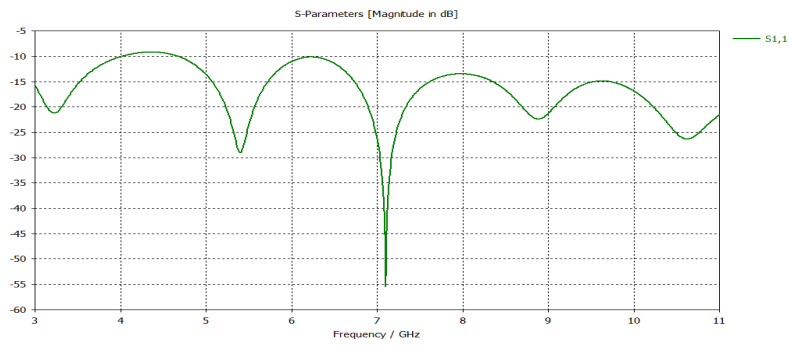

Figure 3. Simulation based variation of reflection coefficient $\left(\mathrm{S}_{11}\right)$ with frequency for UWB single BAVA

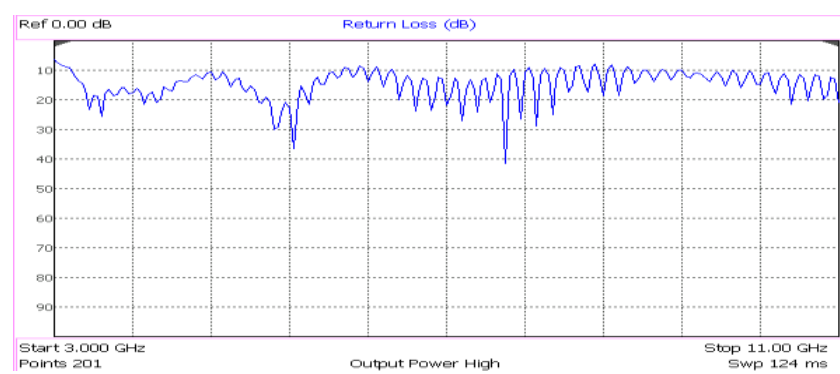

Figure 4. Experimental based variation of reflection coefficient $\left(S_{11}\right)$ with frequency for UWB single BAVA

Bulletin of Electr Eng and Inf, Vol. 8, No. 2, June 2019: $644-652$ 


\subsection{Radiation patterns}

The BAVA radiation patterns represent a good combination of gain and side lobe level, half power bandwidth and angular width at different range of UWB frequency. The maximum gain has been given which is around $10.1 \mathrm{~dB}$ at $7 \mathrm{GHz}$ of frequency. It can be showed in Figure 5.

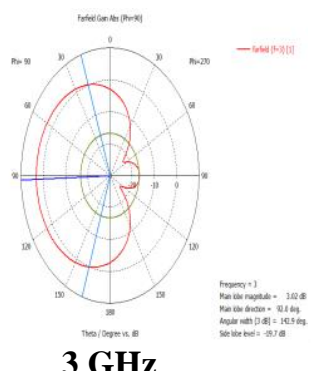

$3 \mathbf{G H z}$

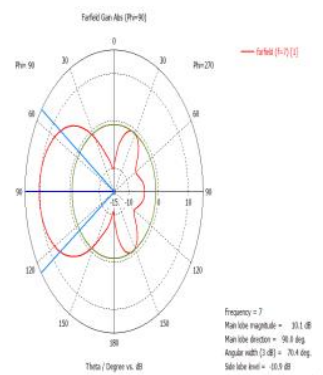

$7 \mathrm{GHz}$

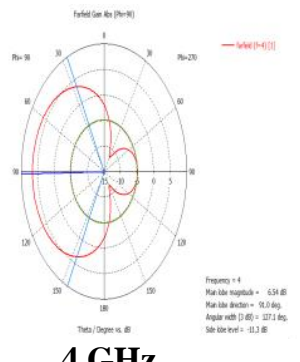

$4 \mathrm{GHz}$

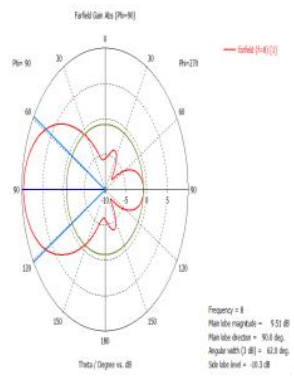

$8 \mathrm{GHz}$

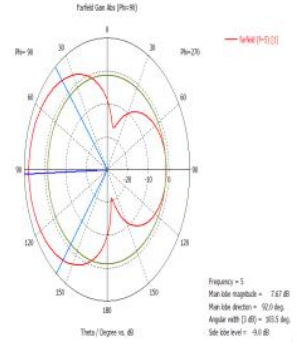

$5 \mathbf{G H z}$

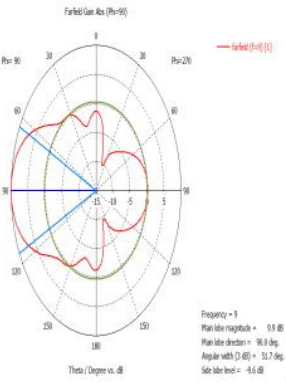

$9 \mathbf{G H z}$

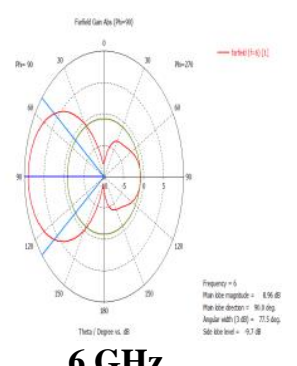

$6 \mathrm{GHz}$

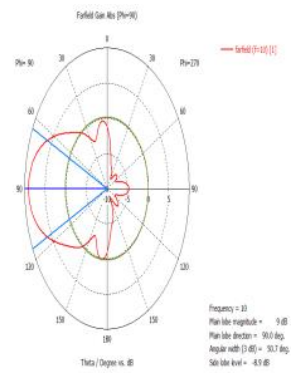

$10 \mathrm{GHz}$

Figure 5. Polar radiation patterns of UWB single BAVA

\subsection{Voltage standing wave ratio}

The depicted Figure 6 based on simulation result and Figure 7 based on experimental result which represent voltage standing wave ratio of a BAVA. It is operating under UWB frequency and the magnitude of VSWR should be less than 2. It means that the reflection effect which generated from the BAVA can be minimized. The graph of VSWR has shown a good arrangement of ratio which is about 1 and it is better for imaging system.

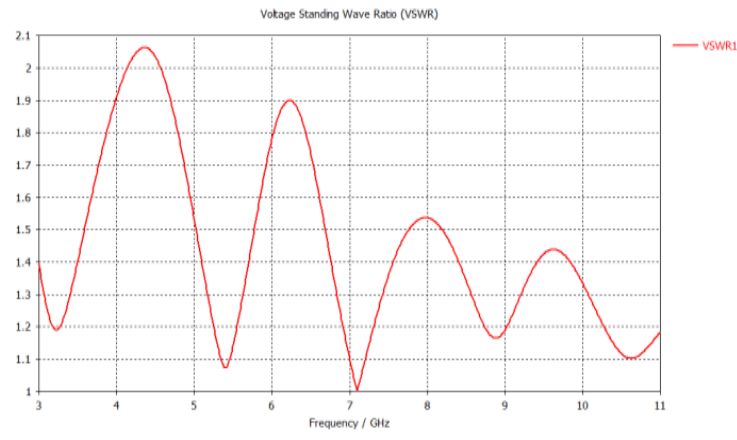

Figure 6. Simulation based VSWR of single element of BAVA

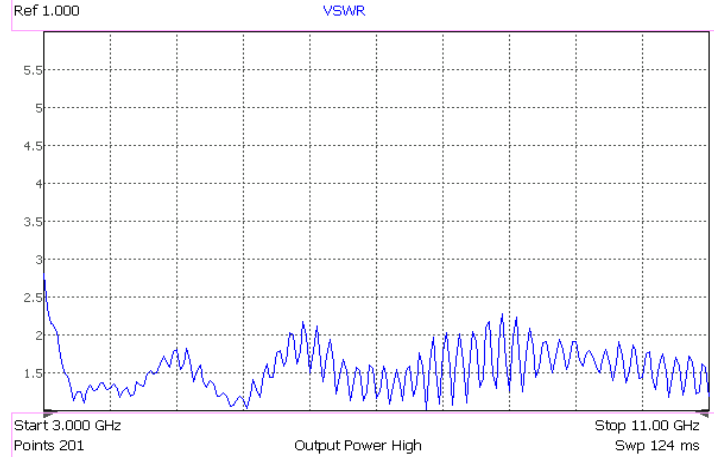

Figure 7. Experimental based VSWR of single element of BAVA

\section{FOUR ELEMENTS ARRAY DESIGN IN PLANAR ARRANGEMENT}

Four elements of BAVA array in planar arrangement is introduced in this research. In several imaging applications the requirement of antenna cascading because of demand in stability for good reflection results so the antenna array in planar plane is introduced as presented in Figure 8. 


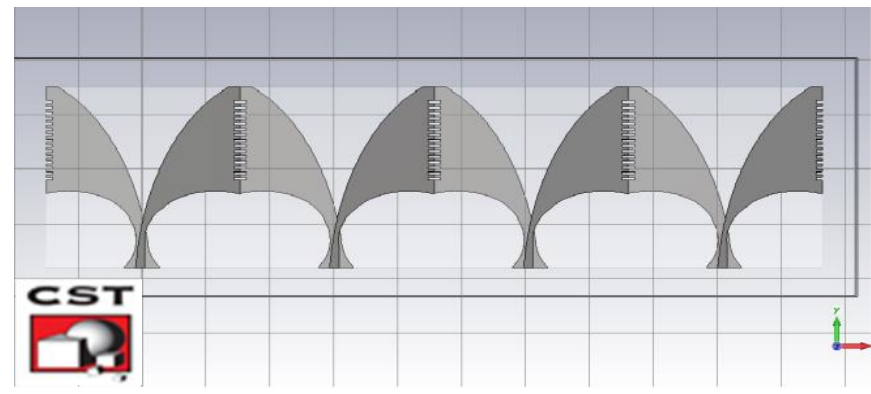

Figure 8. Four element of BAVA array in planar plane arrangement [17]

\subsection{Reflection coefficient}

The $S_{11}$ parameter of four elements of BAVA array in planar plane arrangement is presented as shown in Figure 9. It covers whole UWB frequency and giving a satisfactory reflection coefficient on all ports as represent in Table 2.

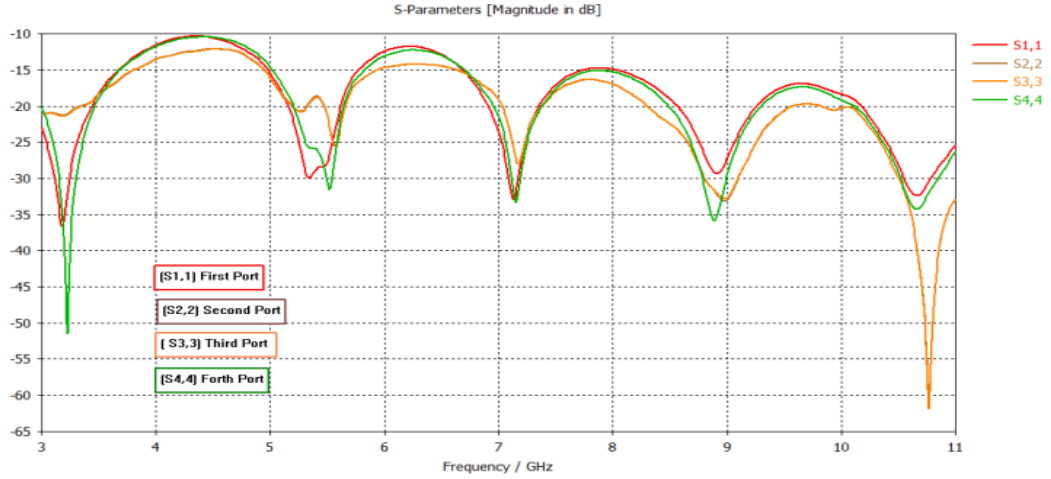

Figure 9.Variation of reflection coefficient $\left(S_{11}\right)$ with frequency for 4-element BAVA array in planar plane arrangement

Table 2. S-Parameter of 4-element of BAVA array in planar plane

\begin{tabular}{|c|c|c|c|}
\hline \multicolumn{4}{|c|}{ S-Parameter (dB) Four Elements in Planar plane Configuration } \\
\hline 1-Port & 2-Port & 3-Port & 4-port \\
\hline-36.65 & -60.89 & -61.90 & -51.27 \\
\hline
\end{tabular}

\subsection{Radiation patterns}

The representation of 4-elements of planar BAVA in term of gain is presented in Table 3. It gives a good combination of gain at $7 \mathrm{GHz}$ to $8 \mathrm{GHz}$ frequency range at all ports.

Table 3. Gain of 4-element of BAVA array in planar plane

\begin{tabular}{cccccc}
\hline \multicolumn{5}{c}{ Gain $(\mathrm{dB})$ Four Elements in Planar plane Configuration } \\
\hline S.No. & Frequency & 1Port & 2Port & 3Port & 4Port \\
1 & $3 \mathrm{GHz}$ & 3.54 & 4.09 & 4.18 & 2.96 \\
2 & $4 \mathrm{GHz}$ & 6.41 & 6.26 & 6.28 & 6.11 \\
3 & $5 \mathrm{GHz}$ & 7.74 & 7.50 & 7.34 & 7.08 \\
4 & $6 \mathrm{GHz}$ & 8.45 & 7.54 & 7.60 & 8.18 \\
5 & $7 \mathrm{GHz}$ & 9.13 & 7.64 & 7.61 & 8.63 \\
6 & $8 \mathrm{GHz}$ & 9.17 & 8.76 & 7.76 & 8.98 \\
7 & $9 \mathrm{GHz}$ & 8.82 & 7.55 & 7.53 & 8.65 \\
8 & $10 \mathrm{GHz}$ & 8.29 & 7.39 & 7.46 & 8.07 \\
\hline
\end{tabular}




\subsection{Voltage standing wave ratio}

The VSWR of 4-element of BAVA array in planar plane arrangement is offered in Figure 10. It is operating under UWB frequency range and giving reasonable magnitude on all ports as depicted in Table 4 respectively.

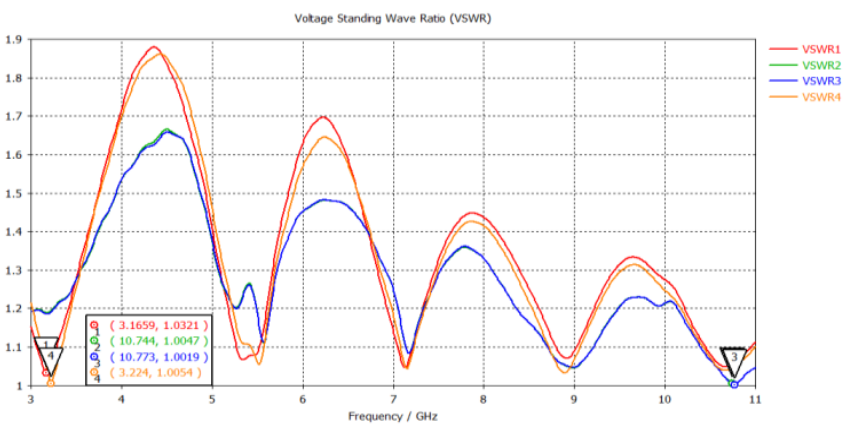

Figure 10. VSWR of 4-element of BAVA in planar plane arrangement

Table 4. VSWR of 4-element of BAVA array in planar plane

\begin{tabular}{cccc}
\hline \multicolumn{2}{l}{ VSWR Four Elements in Planar Plane } & Configuration \\
\hline 1-Port & 2-Port & 3-Port & 4-port \\
1.032 & 1.004 & 1.001 & 1.005
\end{tabular}

\section{FOUR ELEMENTS ARRAY DESIGN IN H-PLANE ARRANGEMENT}

In H-plane arrangement the 4-elements of BAVA array is presented in this paper as shown in Figure 11. In many radar and imaging applications the requirement of high gain and stability so, the configuration in H-plane is more suitable for perceive the good results.

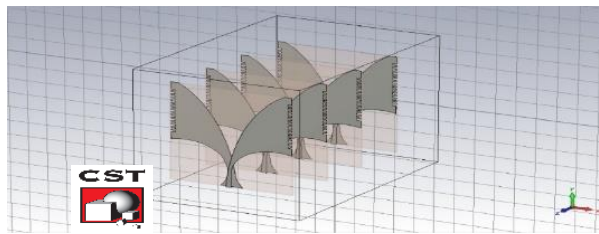

Figure 11. Four element of BAVA array in H-plane arrangement

\subsection{Reflection coefficient}

The reflection coefficient of 4-elements of BAVA array in H-plane arrangement is presented as shown in Figure 12. It covers almost whole UWB frequency and giving a satisfactory reflection coefficient on all ports as represent in Table 5.

Table 5. S-Parameter of 4-element of BAVA array in H-plane

\begin{tabular}{|c|c|c|c|}
\hline \multicolumn{4}{|c|}{ S-Parameter (dB) Four Elements in H-plane Configuration } \\
\hline 1-Port & 2-Port & 3-Port & 4-port \\
\hline-42.17 & -46.22 & -42.25 & -48.21 \\
\hline
\end{tabular}




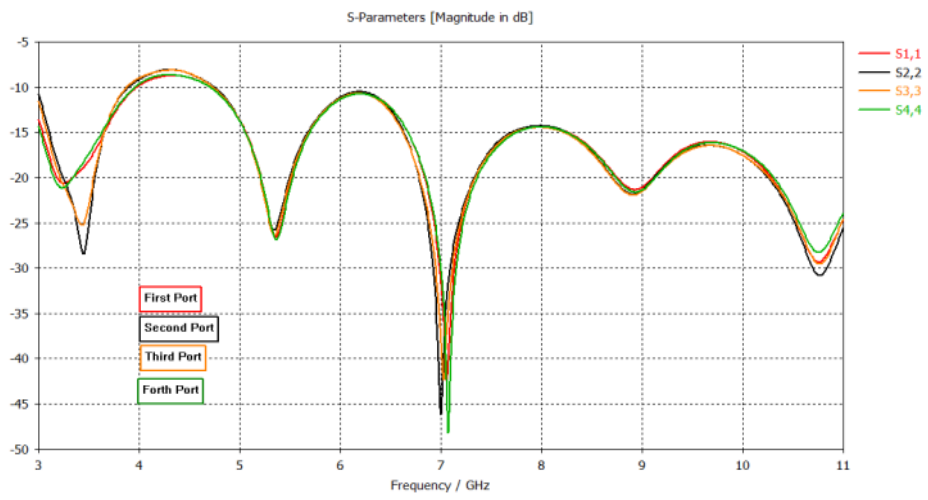

Figure 12. Variation of reflection coefficient $\left(\mathrm{S}_{11}\right)$ with frequency for 4-element BAVA array in H-plane arrangement

\subsection{Radiation patterns}

The 4-elements of BAVA array in H-plane configuration in capacity of gain are presented in Table 6. It is showing a very good combination of gain under frequency range of $7 \mathrm{GHz}$ to $9 \mathrm{GHz}$ at all ports.

Table 6. Gain of 4-element of BAVA array in H-plane Gain $(\mathrm{dB})$

\begin{tabular}{cccccc}
\multicolumn{7}{c}{ Four Elements in H-plane Configuration } \\
\hline S.No. & Frequency & 1Port & 2Port & 3Port & 4Port \\
1 & $3 \mathrm{GHz}$ & 3.86 & 3.08 & 3.14 & 3.93 \\
2 & $4 \mathrm{GHz}$ & 6.53 & 5.67 & 5.82 & 6.68 \\
3 & $5 \mathrm{GHz}$ & 7.48 & 6.95 & 7.06 & 7.73 \\
4 & $6 \mathrm{GHz}$ & 8.82 & 8.53 & 8.55 & 8.87 \\
5 & $7 \mathrm{GHz}$ & 10.20 & 9.06 & 9.33 & 10.30 \\
6 & $8 \mathrm{GHz}$ & 9.4 & 9.21 & 9.33 & 9.52 \\
7 & $9 \mathrm{GHz}$ & 9.76 & 9.45 & 9.45 & 9.83 \\
8 & $10 \mathrm{GHz}$ & 8.94 & 8.71 & 8.78 & 9.26 \\
\hline
\end{tabular}

\subsection{Voltage standing wave ratio}

The voltage standing wave ratio of 4-element of BAVA array in H-plane array configuration is obtained in Figure 13. It is operating under UWB frequency range and giving practical magnitude on all ports as described in Table 7.

Table 7. VSWR of 4-element of BAVA array in H-plane

\begin{tabular}{|c|c|c|c|}
\hline \multicolumn{4}{|c|}{ VSWR Four Elements in H-plane Configuration } \\
\hline 1-Port & 2-Port & 3-Port & 4-port \\
\hline 1.018 & 1.016 & 1.032 & 1.039 \\
\hline
\end{tabular}

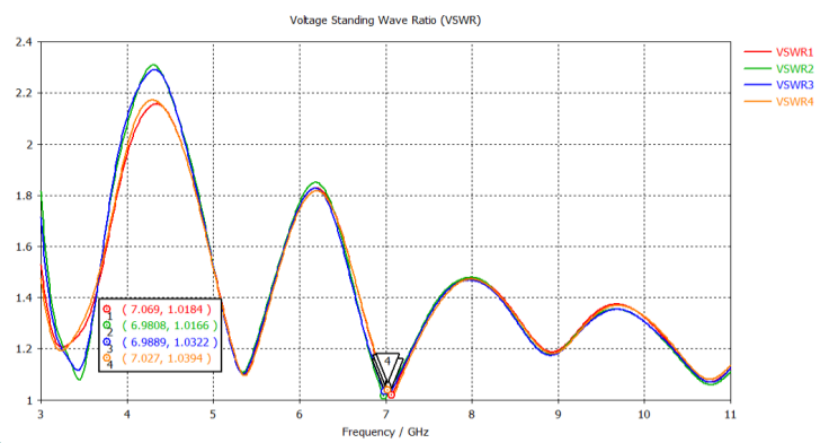

Figure 13. VSWR of 4-element of BAVA in H-plane arrangement 


\section{COMPARISION OF BAVA ARRAY IN PLANAR PLANE WITH H-PLANE}

The comparison analysis of BAVA array in two different planes has been reported in this paper. It is confirmed that the four element array in planar plane works well under low frequency which around $3 \mathrm{GHz}$ to $3.5 \mathrm{GHz}$ with lowest return losses that is $-36 \mathrm{~dB}$ to $-51 \mathrm{~dB}$ respectively. In H-plane configuration the four elements works well under frequency range of $6.8 \mathrm{GHz}$ to $7.2 \mathrm{GHz}$ with the lowest return of $-42 \mathrm{~dB}$ to $-48 \mathrm{~dB}$ as shown in Table 8 respectively. Based on simulation results the operating frequency of 4 -element of BAVA array in planar plane configuration is shifting and turn out to be lower because the change in distance called wavelength, when it is increase the frequency is become lower side. In H-plane at all ports gives better radiation which are fundamental requirement of any array system in a capacity of gain and antenna directivity under frequency range of $7 \mathrm{GHz}$ as compared to planar plane configuration as depicted in Table 9. The magnitude of VSWR should be less than 2 for each operating frequency of an antenna. Regarding the results of simulation, the planar configuration gives good voltage ratio around 1.03 to 1.2 at the lowest UWB frequency range that is $3 \mathrm{GHz}$ to $3.5 \mathrm{GHz}$ for all ports but in $\mathrm{H}$-plane the voltage ratio increases and giving the values which are greater than 2 under specific range of frequency such as $4 \mathrm{GHz}$ to $4.7 \mathrm{GHz}$ respectively.

Table 8. S-Parameter of 4-element of BAVA array in planar plane and H-plane

\begin{tabular}{ccccc}
\hline \multicolumn{5}{c}{ S-Parameter (dB) } \\
\hline Planar Configuration & 1-Port & 2-Port & 3-Port & 4-port \\
& -36.65 & -60.89 & -61.90 & -51.27 \\
H-plane Configuration & -42.17 & -46.22 & -42.25 & -48.21 \\
\hline
\end{tabular}

Table 9. Gain of 4-element of BAVA array in planar plane and H-plane

\begin{tabular}{|c|c|c|}
\hline \multicolumn{3}{|c|}{ Gain $(\mathrm{dB})$ at Frequency $=7 \mathrm{GHz}$} \\
\hline & 1-Port & 9.13 \\
\hline Planar Pla & 2-Port & 7.64 \\
\hline \multirow[t]{3}{*}{ Configuration } & 3-Port & 7.61 \\
\hline & 4-port & 8.63 \\
\hline & 1-Port & 10.2 \\
\hline \multirow{3}{*}{$\begin{array}{c}\text { H-plane } \\
\text { Configuration }\end{array}$} & 2-Port & 9.06 \\
\hline & 3-Port & 9.33 \\
\hline & 4-port & 10.30 \\
\hline
\end{tabular}

\section{CONCLUSION}

In this work UWB-BAVA antenna has been designed and developed. The parametric evolution of single element of BAVA has been carried out using CSTMWS. Further it has been investigated through experimentally via vector network analyzer (VNA). The single element of BAVA antenna has been attained the appropriate value of return loss better than $-10 \mathrm{~dB}$ and achieved satisfactory VSWR in both combinations but the value of VSWR is marginally high at frequency $4.2 \mathrm{GHz}$ to $4.5 \mathrm{GHz}$ in range. In order to minimize the reflection effect which generated by the antenna so the value of VSWR should be less than 2. Additional in this research the arrangement of four elements of BAVA in planar plane and H-plane has been introduced. The comparative study based on simulation results via CSTMWS. According to the outcomes excellent return loss has been produced in planar plane arrangement while at $7 \mathrm{GHz}$ of frequency high amount of gain is achieved approximately $10.20 \mathrm{~dB}$ in H-plane arrangement at all ports of an antenna as compared to planar plane arrangement.In the light of several parameters it has been confirmed that the design arrangements of an antenna can produce an effect on whole performane. H-plane arrangement of BAVA elements can be more appropriate for phased array antenna where the condition of stable high gain as well as planar plane arrangement can be suitable for snow radar where the requirement of high reflection. Future work of this research to counter the effects in order to decrease mutual coupling among inter elements.

\section{ACKNOWLEDGEMENTS}

The authors acknowledge the financial assistance of this research which is supported by the IIUM Research Management Center (RMC) via Research Initiative Grant Scheme (RIGS) with the grant number RIGS 15-147-0147 and RIGS 16-067-0231.

\section{REFERENCES}

[1] R. Natarajan, J. V. George, M. Kanagasabai and A. Kumar Shrivastav, "A Compact Antipodal Vivaldi Antenna for UWB Applications," in IEEE Antennas and Wireless Propagation Letters, vol. 14, pp. 1557-1560, 2015. 
[2] Lin S, Yang S, Fathy AE, Elsherbini A. Development of a novel UWB Vivaldi antenna array using SIW technology. Progress In Electromagnetics Research. 2009;90:369-84.

[3] J. Sorocki, I. Piekarz, S. Gruszczynski and K. Wincza, "Approach to the design of wideband antenna arrays with reduced coupling between elements," 2017 Conference on Microwave Techniques (COMITE), Brno, 2017, pp. 1-4.

[4] Shaikh FA, Khan S, Alam Z, Hassan A, Hashim A, Badron K, Yaacob M. High Gain UWB Horn Antenna for Concealed Metal Detection and Microwave Imaging Application. Sindh University Research Journal (Science Series). 2018 Oct 8;50(3D):161-4.

[5] S. Imtiaz, A. Khatri, I. Motan, F. A. Shaikh and S. Khan, "Finger-Worn Assistive Device for Detection Tracking and Recognition," 2018 7th International Conference on Computer and Communication Engineering (ICCCE), Kuala Lumpur, 2018, pp. 470-475.

[6] J. Bourqui, M. A. Campbell, J. Sill, M. Shenouda and E. C. Fear, "Antenna performance for ultra-wideband microwave imaging," 2009 IEEE Radio and Wireless Symposium, San Diego, CA, 2009, pp. 522-525.

[7] Tiang SS, Hathal MS, Anwar NS, Ain MF, Abdullah MZ. Development of a compact wide-slot antenna for early stage breast cancer detection featuring circular array full-view geometry. International Journal of Antennas and Propagation. 2014.

[8] Khor WC, Bialkowski ME, Abbosh A, Seman N, Crozier S. An ultra wideband microwave imaging system for breast cancer detection. IEICE Transactions on Communications. 2007 Sep 1;90(9):2376-81.

[9] Perdana MY, Hariyadi T, Wahyu Y. Design of Vivaldi Microstrip Antenna for Ultra-Wideband Radar Applications. InIOP Conference Series: Materials Science and Engineering 2017 Mar (Vol. 180, No. 1, p. 012058). IOP Publishing.

[10] E. Gazit, "Improved design of the Vivaldi antenna," in IEE Proceedings $H$ - Microwaves, Antennas and Propagation, vol. 135, no. 2, pp. 89-92, April 1988.

[11] SHAIKH F, KHAN S. Design and Optimization of Ultra-Wideband Antipodal Vivaldi Antenna for Radar and Microwave Imaging Application. Sindh University Research Journal (Science Series). 2018 Oct 8;50(3D):06-9.

[12] Elsheakh DM, Eltresy NA, Abdallah EA. Ultra Wide Bandwidth High Gain Vivaldi Antenna for Wireless Communications. Progress In Electromagnetics Research. 2017;69:105-11.

[13] M. Moosazadeh, S. Kharkovsky, J. T. Case and B. Samali, "Improved Radiation Characteristics of Small Antipodal Vivaldi Antenna for Microwave and Millimeter-Wave Imaging Applications," in IEEE Antennas and Wireless Propagation Letters, vol. 16, pp. 1961-1964, 2017.

[14] I. T. Nassar and T. M. Weller, "A Novel Method for Improving Antipodal Vivaldi Antenna Performance," in IEEE Transactions on Antennas and Propagation, vol. 63, no. 7, pp. 3321-3324, July 2015.

[15] A. Elboushi et al., "Design of UWB antenna array for through-wall detection system," 2013 IEEE Symposium on Wireless Technology \& Applications (ISWTA), Kuching, 2013, pp. 349-354.

[16] S. Ahsan, P. Kosmas, I. Sotiriou, G. Palikaras and E. Kallos, "Balanced antipodal Vivaldi antenna array for microwave tomography," 2014 IEEE Conference on Antenna Measurements \& Applications (CAMA), Antibes Juan-les-Pins, 2014, pp. 1-3.

[17] F. A. Shaikh et al., "Comparative Analysis of UWB Balance Antipodal Vivaldi Antenna for Array Configuration," 2018 7th International Conference on Computer and Communication Engineering (ICCCE), Kuala Lumpur, 2018, pp. 124-129.

[18] F. A. Shaikh et al., "Detection and analysis of metal impairment inside wall using UWB Modified Antipodal Vivaldi Antenna," 2017 4th IEEE International Conference on Engineering Technologies and Applied Sciences (ICETAS), Salmabad, 2017, pp. 1-5.

[19] N. Ardelina, E. Setijadi, P. H. Mukti and B. Manhaval, "Comparison of array configuration for Antipodal Vivaldi antenna," 2015 International Conference on Radar, Antenna, Microwave, Electronics and Telecommunications (ICRAMET), Bandung, 2015, pp. 40-45.

[20] F. A. Shaikh et al., "Ultra-wideband antipodal Vivaldi antenna for radar and microwave imaging application," 2017 IEEE 3rd International Conference on Engineering Technologies and Social Sciences (ICETSS), Bangkok, 2017, pp. 1-4.

[21] A. M. Abbosh and M. E. Bialkowski, "Design of Ultrawideband Planar Monopole Antennas of Circular and Elliptical Shape," in IEEE Transactions on Antennas and Propagation, vol. 56, no. 1, pp. 17-23, Jan. 2008.

[22] Hien $\mathrm{Chu} \mathrm{Ba}, \mathrm{H}$. Shirai and C. D. Ngoc, "Analysis and design of antipodal Vivaldi antenna for UWB applications," 2014 IEEE Fifth International Conference on Communications and Electronics (ICCE), Danang, 2014, pp. 391-394.

[23] F. A. Shaikh, S. Khan, A. Z. Alam, M. H. Habaebi, O. O. Khalifa and T. A. Khan, "Design and analysis of 1-to-4 wilkinson power divider for antenna array feeding network," 2018 IEEE International Conference on Innovative Research and Development (ICIRD), Bangkok, 2018, pp. 1-4.

[24] CST Microwave Studio, Ver. 2015 Computer Simulation Technology, Framing-ham, MA, USA.

[25] Shaikh FA, Khan S, Zaharudin Z, Alam AZ, Rahman FD, Badron KB, Baillargeat D, Yaacob MB, Shahid Z. Recognition of Metal Objects inside Wall using Antipodal Vivaldi Antenna. Indonesian Journal of Electrical Engineering and Computer Science (IJEECS). 2018 Jul 1;11(1):27-35. 